\title{
Los nombres del futuro, una propuesta
}

\section{Naming the Future, a Proposal}

\author{
Mónica Ramón Ríos \\ Pratt Institute, Nueva York \\ mriosvas@pratt.edu
}

\section{Resumen}

Este ensayo desentraña cómo y si acaso la literatura responde o se pliega al despertar político en Chile. En otras palabras, ¿qué significa despertar con el lenguaje? A pesar de que la respuesta ha sido lenta, las literaturas tienen un rol fundamental de escribir las heliografías del futuro y dar cuerpo a comunidades que están a la espera (de justicia y de constituirse). En la revuelta, esas comunidades emergieron desde los subterráneos del orden neoliberal poniendo en simultánea acción el goce y el sacrificio. La propuesta es que la lengua literaria no es potencialidad, sino potencia, una lengua que pone en acción el presente del colectivo para dar nombre a los espacios emancipatorios que transitan a las sombras del Estado/mercado. Utilizando metodologías críticas de los estudios culturales, teorías del otro utopianismo y calibraciones del poder deseante del lenguaje poético, se critica la literatura neoliberal y sus prácticas extractivistas con el objetivo de proponer otras metodologías estéticas que abran espacios al respirar del otro.

Palabras clave: Literatura chilena, revuelta, movimiento destituyente, momento constituyente, utopismo.

\section{Abstract}

This essay unravels how and if literature responds to the political awakening in Chile. In other words, what does it mean "to be woke" with language? The response is a deep reflection on how literatures have a fundamental role in writing the blueprints of the future and giving shape to communities that are waiting (for justice and to be constituted). In the revolt, these communities emerged from the underground of the neoliberal order, enabling the simultaneous enactment of goce and sacrificio. The proposal is that the literary language is not a potentiality, but a potentia, a language that enacts the present of the collective to give a name to the emancipatory spaces that exist in the shadows of the State and the market. Using critical methodologies from cultural studies, theories of the other utopianism and calibrations of the desiring power of poetic language, neoliberal literature and its extractivist practices are criticized to propose other aesthetic methodologies that open spaces for breathing with the other.

Keywords: Chilean literature, revolt, destituting movement, constituting moment, utopianism. 
La revuelta social es también una revuelta de los sentidos. En este ensayo, quiero desentrañar cómo y si acaso la literatura responde o se pliega al despertar político en Chile. En otras palabras, ¿qué significa despertar con el lenguaje? Para responderla es imposible pensar en una sola literatura, y tal vez sea ese el primer efecto que generaliza la asonada popular. El 18 de octubre de 2019 hizo emerger un mundo artístico denso y amplio, practicado a las sombras del Estado y el mercado. Por otra parte, como una persona que transita entre la escritura de ficción, el ejercicio académico y la práctica editorial, concibo la literatura no solo dentro del marco de la página o la hora que duran las lecturas, sino también con sus contextos, modos en que circulan y los procesos de su producción. Por cierto, la literatura que produce en oposición a la estructura de mercado existía antes del 18 de octubre y tiene una larga historia, también subterránea con su propio archivo espectral, que se materializa a través de escrituras y editoriales que anteponen los afectos, el trabajo colectivo y la formación de una contracultura - a diferencia de autores y editoriales que anteponen el lucro, las jerarquías en la división del trabajo, el cambio de estética o línea editorial según la temperatura de los tiempos y el networking-.

El movimiento del 18 de octubre dejó "algo" obsoleto y puja por reemplazarlo por "otra cosa". Ese "algo" tiene su origen en la transa noventera, la profunda neoliberalización de la práctica editorial (incluso la independiente) en el siglo xxI, el consecuente mundo literario homogéneo y tácticas de mercado que inflan las capacidades numéricas del cuerpo lector chileno. Como parte de la misma tendencia, se suman los vínculos mercantiles transnacionales, la eliminación de la libertad en la prensa cultural y la ideologización anticrítica en las aulas universitarias. Cómo se reemplazaron las prácticas contraculturales de la poesía, la literatura y la performance chilena de los ochenta es parte de la deuda que la asonada popular viene a cobrarle a esa literatura-moneda. ${ }^{1}$

Esa "otra cosa" que adviene en su reemplazo trae un ámbito diverso de legitimación de la práctica artística, incluida la literatura, sin vínculo alguno —o de oposición u oblicuos - con los representantes de las elites gerenciales. Esa "otra cosa", sin embargo, todavía no tiene nombre. Es una potencialidad y es una potencia. Es una potencialidad, siguiendo a Aristóteles y en el análisis que hace Giorgio Agamben en "On Potentiality", porque es un punto de inflexión en los bordes de un cambio, que podría materializarse (o no) en ejercicios literarios diversos. El afecto que nace de la potencialidad es la zozobra, porque el cambio es todavía un espectro. Pero esa "otra cosa” es también una potencia, una fuerza que modela las posibilidades para una literatura que sea acción. Como sintetiza Verónica Gago sobre "la potencia feminista" y que yo traslado acá a la literatura: "No existe la potencia en abstracto (no es lo

1 Y que causó una serie de delirios apocalípticos en autores cercanos a la derecha, como Arturo Fontaine, Rafael Gumucio y Matías Rivas. Más sobre esto en Ríos, "Las metáforas son insuficientes". 
potencial en términos aristotélicos). [...] es una capacidad deseante. Esto implica que el deseo no es lo contrario de lo posible, sino la fuerza que empuja lo que es percibido colectivamente y en cada cuerpo como posible" (La potencia feminista 10). Esa "otra cosa" que viene en reemplazo de lo consabido es potencia porque lo que todavía no tiene nombre es, justamente, el ámbito de la literatura.

En esa falta de nombre que es emergencia, acción y revuelta del campo literario mismo radica la potencia de las literaturas que me interesa invocar, aunque no analizar, en este ensayo. No es una labor fácil; podría, eso sí, explicar la demora de cierta literatura a responder sesudamente a la revuelta. ${ }^{2}$ De manera generosa, entiendo la demora como un reclamo por el tiempo, como un restarse de la máquina productiva - y que en la literatura se asimila a la inmediatez del periodismo-, demanda similar a la de la protesta y la asamblea. Pero en la literatura, y a diferencia de las protestas que explicitan demandas con la presencia y el cuerpo, la falta de respuesta "a tiempo" se confunde con silencio. Y ese silencio subestima una de las potencias de la literatura, la de ensayar colectivamente los nombres del futuro.

\section{La potencia del nombrar, una propuesta}

Los nombres del habitar futuro no los escribe un individuo de una sola vez y a la perfección. El futuro se escribe bajo entramados que no son rectos como las líneas narrativas de los creative writing programs. Se escriben en la marcha, como un diálogo, a veces oralmente, otras con escritura críptica. Desde el 18 de octubre, han aparecido varias asambleas que, a pesar de la separación de cuerpos, han continuado bajo la cuarentena. Pero el lugar de la asamblea literaria es también el trabajo con el lenguaje, oral o escrito, que apunta a visibilizar lenguas que se presentan como gruñidos apolíticos en el espacio público y que la mediación estética literaria puede (re)presentar y transformar en política.

Es más, la escritura nunca es individual. Como explica Cristina Rivera Garza en su "Desapropiación para principiantes", el lenguaje es un bien colectivo frente al cual la escritora siempre está en deuda (24). Paul Preciado, en la introducción a la edición estadounidense de su Counter-Sexual Manifesto, le suma ese otro aspecto de la potencia literaria, el deseo siempre político, al declarar que el lenguaje no es solamente un instrumento de comunicación, sino también un órgano de la reproducción de la vida. Aquí una cita suya que comenta la potencia interrelacional del lenguaje literario o "lenguaje poético", como lo llama. Traduzco del inglés: "El deseo no es una verdad dada sino un campo social fabricado que puede modificarse invirtiendo en

2 El término "sesudo" lo propone Julieta Marchant en su ensayo "Para qué poetas en tiempos de miseria": "Como si a todo escritor se le exigiera escribir declaraciones sobre el cemento caliente o como si los escritores - en generaldebiéramos responder al unísono a lo que ocurre en nuestros territorios y además sesudamente". 
las herramientas de la metáfora y la imaginación, del lenguaje poético y la experimentación somática” (16).

La imaginación y el deseo en el campo político, a veces llamado utopismo, ha sido criticado y ridiculizado prominentemente desde el marxismo, y más recientemente por los defensores de las transas transicionales o el nuevo conservadurismo chileno. Pero la imaginación y el deseo son herramientas de la literatura; negarlas es negar potencia y poder de acción a la literatura. ${ }^{3}$ Invoco a esos trabajadores que J. Rancière describe en el primer capítulo de su Noche de los proletarios, para quienes el aspecto crítico es no poder "elegir nuestro cansancio", pero cuyo deseo es también la "posibilidad de soñar con otro tipo de trabajo" (8). Esos "trabajadores secretamente enamorados de las cosas inútiles" desertan la imagen del trabajador satisfecho originando un "poeta por venir" (9). Como explicaré en el apartado sobre "el otro utopismo", las literaturas, particularmente en la narrativa de ficción, ${ }^{4}$ tienen un rol fundamental de escribir las heliografías del futuro y dar cuerpo a comunidades que están a la espera. ${ }^{5}$ Hoy esas comunidades se cansaron de esperar y emergieron desde los subterráneos del mundo poniendo en simultánea acción el goce y el sacrificio. En otras palabras, la lengua literaria no es potencialidad, identificada en este ensayo con el sistema literario que se fundamenta en el fracaso de resistir, sino potencia: es una lengua que habita el presente del colectivo para dar nombre a los espacios emancipatorios que transitan a las sombras del Estado/mercado; los nombres irrumpen mediados con el propósito de materializarlos y ponerlos en acción en lenguas y cuerpos. Esta es mi propuesta.

Lo que está en discusión no es solo si acaso una escritura es relevante y comercializable ahora o en el futuro, sino cómo el campo social fabrica qué es literatura; en resumidas cuentas, si el ejercicio estético escrito u oral es entretenimiento y mercado (con su ética individualista, entregada al amo y asociada al éxito), o acción, propuesta y performance ${ }^{6}$ del nombrar. Para este texto, también es pertinente preguntar ¿cómo

3 Hablo de esa negación en mi columna "Que la imaginación colectiva nos libre de sus trabalenguas". Ahí llamo a los escritores que ridiculizan la imaginación en el campo político creadores de "una literatura sin consecuencias". En el párrafo final, recuerdo esa fábula de Paul Vinçard que Jacques Rancière comenta en La noche de los proletarios: "El protagonista, un escritor que decide escribir en las noches después de su jornada laboral, visita al escritor de folletines, el vendido, acongojado de una fatal enfermedad del alma. Lo encuentra en compañía 'del Otro absoluto, del que no vive de sus manos ni de sus pensamientos, pero el de otros'. Concluye: 'quien vive del trabajo de sus manos puede actuar contra el pensamiento del amo o, con su pensamiento, en contra de la materialidad de su trabajo'. Pero quien pone a disposición del capital su pensamiento y su pluma no agota su trabajo únicamente en las metas alcanzadas, en el trabajo bien hecho, sino que debe hacer más, debe alienar lo que tiene de más precioso. 'Un trabajador del pensamiento es una contradicción en los términos que no puede resolverse más que en la muerte o en la servidumbre”.

4 Me concentro en la narrativa y la ficción no solamente porque es cómo somatizo mi trabajo, sino también porque parte de mi proyecto es una defensa de la ficción como la historia de los sin historia. Para una crítica de la separación entre historia y ficción, o historia y mito, ver Édouard Glissant, Caribbean Discourse.

5 En términos de José Esteban Muñoz, pero también recordando la cita de C. L. R. James: "revolutions happen because people wait and wait and try" (anotado en mi cuaderno después de una charla de Ruth Wilson Gilmore, CUNY Graduate Center, abril de 2019).

6 Inserto aquí la palabra performance en el borde y desborde de sus campos semánticos que vinculan la práctica artística de la performance (pienso particularmente en el CADA y el trabajo interdisciplinario entre literatura y acción) y la performance como la usa Judith Butler en su El género en disputa y en Notes Toward a Performative Theory of Assembly, como una puesta en acción (enactment) y su consiguiente efectividad en el campo de lo público y lo político. 
escribir y leer academia, con sus formatos e industria modelados según estrategias para avanzar en la carrera y de, como dijo un colega una vez, encontrar la tesis en el segundo párrafo, después del 18 de octubre? Tomando la invitación de Patricia Espinosa, esto no es un paper. Tengo el privilegio de vivir entre dos mundos, Chile y Estados Unidos, y de no pertenecer enteramente a ninguno de ellos. Asimismo, no practico la especialización profesional, porque experimento la literatura como un constante poner en cuestión los límites de la disciplina y lo real. Dejo entrar en este ensayo ideas sobre "el archivo espectral" en relación con la historia del cine, el ejercicio de mirar y la práctica cinematográfica feminista; "el otro utopismo" y el "vivir distinto" que teoriza Avery Gordon; y sobre todo el potencial político de la ficción para escribir la historia de los sin historia. Si acaso estos vectores se aplican o no a la literatura es objeto de esta dèrive investigativa.

\section{El otro utopismo}

Reinterpreto "utopía" en las líneas propuestas por Avery Gordon en su libro The Hawthorne Archive de 2018. Allí expande la interpretación de lo utópico fuera del limitado rango de una historiografía racializada que va desde Hesíodo y los profetas judíos hasta Thomas More, Saint-Simon y más recientemente Ursula K. Le Guin. ${ }^{8}$ En esa tradición occidental, "utopía" se refiere usualmente a la imaginación de una sociedad perfecta, sobre la base de una crítica social de la actual, y a menudo ubicada en el futuro. Es decir, utopía se refiere simultáneamente a "un mejor lugar" y a "un lugar inexistente", desconectando la representación de lo factible. Debido a esto, lo utópico fue duramente criticado por el materialismo histórico; según Karl Marx y Friedrich Engels, los pensadores de la utopía desestiman las reglamentadas condiciones que determinan el capitalismo. Pero, al decir de Gordon, Herbert Marcuse reflexionó cómo al descartar un argumento por utópico también permitimos una ilimitada intervención de las herramientas que administran y suprimen el pensamiento crítico y las prácticas emancipatorias. Siguiendo a Ernst Bloch, Marcuse se concentra en el "principio activo de la esperanza, donde los individuos y los grupos anticipan, en el pensamiento o en la práctica, su rechazo de la totalidad de la sociedad actual y sus sueños por una sociedad mejor" (Gordon 26, la traducción es mía).

En su libro, Gordon quiere pensar en ese "otro utopismo" (other utopianism). Tal reflexión investiga los distintivos afectos onto-epistemológicos que crean "nuevas formas de vida en los intersticios de un abandono organizado por el Estado" (viII, la traducción es mía). Esa articulación se asemeja a las metodologías del "neoliberalis-

7 Como la entiende Guy Debord.

8 Tengo frente a mí The Utopia Reader. 
mo desde abajo", propuesto por Verónica Gago: ambas crean economías salvajes que desplazan el ethos productivista favorecido por las tradiciones marxistas y socialistas. Estas configuraciones indican un universo alternativo o una civilización poblada por acciones para las cuales no existe todavía un lenguaje. Como otros han notado antes, entre quienes incluyo a Paul Preciado, y a Stefano Harney y Fred Moten, este es el espacio del lenguaje poético y de las narrativas de ficción. José Muñoz, en su Cruising Utopias, argumenta que cada pieza creativa contiene las heliografías de una "forwarddawning futurity" (un alba, una adelantada, un futuro), que no es nada menos que la potencia de una comunidad que ha estado "a la espera" bajo las estructuras de la “esperanza” de vivir mejor. Con las técnicas provistas por las prácticas estéticas, el porvenir puede articularse en el presente, convirtiéndose así en un punto de tensión temporal que a su vez reorganizan la frontera realidad/ficción. Escribe Gordon:

En las zonas de exclusión, encontramos pensamiento y práctica utópicas que son tan transnacionales como locales, orientadas al presente como al pasado y al futuro; que existen cómodamente con especulaciones salvajes como con los momentos colectivos; que se preocupa de la subjetividad y la sociedad como dos importantes objetos de transformación; y que ofrece enriquecedoras e inclusivas nociones de libertad, soberanía y felicidad (VIII).

Así, más que una estructura de la esperanza, la utopía de los márgenes - y que en Chile es subterránea- es una forma de vida que ya está aquí, con su propia historia y su falta de registro, cohabitando con el mundo diseñado por los dueños y sus sirvientes. Como concluye Gordon, en los márgenes utópicos (utopian margins) existe "una comunidad de intelectuales, artistas y escritores viviendo y trabajando en la diferencia; no a la espera de otro mundo, sino estando ya en él” (XI).

\section{Apertura}

¿Cómo comunicarnos literariamente sin la intervención de esas herramientas de aula que circulan de la universidad a los medios de derecha y las editoriales neoliberales normando el mundo público? ¿Cómo, en otras palabras, podemos constituir agencias para las cuales la literatura es una interfaz por la que acceden a ciertas formas de placer o afectos que no pueden representarse por vía de la originalidad, la obra y la autoría??

9 Aquí me desapropio de Paul Preciado cuando distingue dos tipos de agentes sexuales: los realistas, para quienes la sexualidad es la repetición de las leyes que constituyen su identidad de género, y los contrasexuales, que buscan placeres y afectos sin reificar los genitales. Podríamos continuar y desapropiar otra parte de la cita: "Los realistas, hetero u homo, follan en la línea de ensamblaje del mundo biopene/biovagina. El capitalismo sexocolonial automatiza la sexualidad, aumentando la (mayoritariamente impaga) labor y productividad sexual, pero también la producción de las identidades sexuales mainstream que son el blanco del gobierno político y económico. La mayoría de los filósofos, psicólogos y sociólogos son realistas sexuales" (10). Cámbiese "follar" por "escribir" e imagínese a qué correspondería los otros nombres de la sexualidad genital. 
Mis preguntas apuntan a pensar la literatura en el contexto de la crisis del neoliberalismo que se manifestó el 18 de octubre, pero también durante la administración de la pandemia y las cuarentenas. Ambos están conectados por la implementación de los "estados de emergencia". El que se implementa ahora mismo bajo la pandemia ha servido para blanquear los instrumentos de violación a los derechos humanos perfeccionados en la primera. ${ }^{10}$ Después de que atestiguamos cómo el patriarcado materializaba al fin su fantasía del control irrestricto sobre la población y la consecuente emergencia de comunidades de cuidado a las sombras del Estado, nuestro presente se articula sobre los mecanismos de la "apertura". Las administraciones estatales del mundo se han apropiado del término para crear una nueva normalidad en la que el Estado no solo vela por "la salud de la economía", sino que materializa sus deseos de reprimir las demandas de la población bajo la justificación de la emergencia sanitaria. Esa "apertura” pone en marcha una de las actuales "pedagogías de crueldad" (Segato), el foco en los índices y los cuerpos como cifras. Judith Butler explicó uno de los retruécanos lingüísticos que usan los Estados para justificar su control: durante la pandemia, la salud de la economía es más importante que la salud de las personas, y se consigue la primera en detrimento de la última, en particular de las minorías raciales, sexuales y étnicas (en la charla de Puerto de Ideas del 23 de julio de 2020). Así, la población se transforma en una colectividad de cuerpos medibles (basado en su nivel de productividad, incluido el acceso a un seguro de salud pagado) que determinan no solo quién tiene derecho a la vida, sino también a quién debemos matar (las y los prisioneros políticos, por ejemplo) y sobre todo a quién dejamos morir (las y los viejos, por ejemplo).

En contraste con los contados llamados a antologías y la publicación de cuentos y novelas escritos con los pies en la Plaza Dignidad - pienso en "Fábula del falso cardumen de pirañas", de Carlos Labbé, escrito y publicado la primera semana de la revuelta, Satancumbia, de Rodrigo Miranda, escrito durante la revuelta y que será publicado en octubre de $2020,{ }^{11}$ el sinnúmero de lenguaje poético bajo capas de pintura en el edificio del GAM y las lecturas que ocuparon las calles-, durante la pandemia, las y les escritores recibimos varios llamados a publicar en antologías sobre pandemia y confinamiento, y las y les narradores llenaron las estanterías virtuales. Esto trae a la luz aspectos ideológicos importantes de la labor literaria.

Algunas escritoras y escritores, entre los que me cuento, experimentaron la revuelta y la reacción del mundo literario como una puesta al día con una ética/poética practicada desde hacía mucho. Antes, bajo un contexto realista que evitaba la revuelta de los sentidos, éramos el otro necesario para definir los caminos acostumbrados por los cuales "convertirse" en escritor/a. Quienes antes habíamos denunciado de manera

10 Los militares en las calles, el control de movimiento, la suspensión del derecho a reunirse y, como podemos ver en el Wallmapu, las prácticas del terrorismo de Estado para defender a los empresarios frente al alzamiento de las demandas populares.

11 Al momento de escribir el artículo. 
pública y en reuniones gremiales las prácticas neoliberales que unían literatura con Estado securitario y con platas de proveniencias dudosas, fuimos excluidos de la circulación literaria nacional, en ocasiones con acciones explícitas. Estas escrituras no requerían restarse de "escribir sesudamente", sino que vieron con gozo la necesidad generalizada de ponerse al día con lenguajes nunca hablados ni actuados por el ámbito literario.

Otro aspecto ideológico que me parece interesante destacar es la relación que la actividad literaria tiene con el tiempo y las labores de cuidado. La profusión de los escritos del encierro no son únicamente efecto del tiempo que supuestamente se gana por "quedarse en casa". Tal como han vocalizado los grupos y colectivos feministas, para muchas y muches la casa no es un refugio, sino que, más parecido a una prisión, es un espacio violento y disciplinador de diferencias y disidencias. Asimismo, muchas escritoras que llevaban a cabo labores de cuidado las vieron intensificadas durante la cuarentena, y no solo dentro de sus casas, sino también en las ollas comunes y la organización comunitaria. Si el trabajo literario de estas personas se realiza restándole horas al sueño y llevando al límite la relación entre la reproducción social y el trabajo, no podemos decir que en la cuarentena "hay más tiempo". O por lo menos no para la mayoría.

La cuestión es más complicada y deja en evidencia cómo la literatura contribuye a quitar valor a las labores de cuidado al promover un ejercicio "en solitario", naturalizar "el cuarto propio" y crear una partición falsa dentro de los movimientos al definir luchas históricas del feminismo proletario, como la comunidad familiar y la maternidad ${ }^{12}$ bajo una rúbrica de clase alta. Antes en este ensayo expuse cómo la circulación literaria tendía a imponer la homogeneidad de voces y estéticas. Sin embargo, es momento de aclarar que esa homogeneidad se logra únicamente imponiendo y a veces exagerando diferencias hasta crear divisiones socialmente fabricadas que pueden incluso adquirir dimensiones de mitos fundacionales. Aquellas particiones (el término se lo escuché a la activista antiprisión Ruth Wilson Gilmore), cabe apuntar, solo sirven para debilitar las coaliciones potenciales del movimiento anticapitalista, anticolonial y antipatriarcal.

Ilumino el problema del tiempo y las labores de cuidado en el ejercicio intelectual y literario ampliando los vectores propuestos por Sarah Ahmed en su libro Queer Phenomenology. En su análisis, Ahmed revela cómo el trabajo intelectual que sucede desde el escritorio, con sus lápices, cuadernos, libros, ventanas y otras herramientas a través de las que Edmund Husserl se orienta al inicio de su trabajo filosófico

12 Por ejemplo, en la bibliografía actual, se crea una partición falsa entre la mujer sin hijos y las que cuidan niños, propios o no. No considera la politización de la maternidad de Gabriela Mistral en Poema de Chile, también escenificada por Gabriela Bussenius en su largometraje de 1917, que aboga por el traspaso de conocimientos de boca en boca de mujer, ni las solidaridades que estas dos mujeres crean entre el movimiento de mujeres y los pueblos originarios (más sobre esto, en mi tesis doctoral "El archivo espectral"). María Moreno en Oración, libro que politiza las relaciones familiares, lo llama "un amor sin nombre". 
Fenomenología, apuntan hacia el afuera y, por lo tanto, de espaldas a la casa, donde otras personas, presuntamente mujeres, asumen las labores de cuidado. Ese olvido de lo próximo - las actividades de las habitaciones y la cocina-, esa omisión de los fundamentos para la existencia del escritorio y el cuatro propio revelan una zona de exclusión marcada por el género, pero también de clase y raza incorporada a la disciplina escritural. Si ampliamos esa reflexión a la vida colectiva, y como ha dejado en evidencia la crisis del coronavirus, también la masa de escritorios privados depende de las labores de cuidado públicas, que involucran trabajo manual, trabajadoras de la salud, el cuidado de las personas más pequeñas y las más viejas. La orientación de la literatura en términos sociales omite esa labor, porque todavía existe primariamente en ese lugar abstracto del ejercicio en solitario, sin cuerpo y producto de la originalidad. En otras palabras, olvida la presencia del otro, la necesidad de la presencia del otro para la existencia individual, y lo reemplaza por la representación del otro con su consecuente economía extractivista. La literatura escrita lleva inscrita la ética capitalista y para desmarcarse de ella es necesaria una crítica profunda al sistema que excluye a quienes cuidan las bases de la cohesión social.

Mientras desde arriba se fomenta una crisis para acondicionar el avance del neoliberalismo, en los bajos se fortalece la chispa de los sobrevivientes, la acción popular impelida por los vacíos que deja un Estado que se limita a administrar los servicios entregados por privados a privados. Esas comunidades, cuya vida se organiza en torno a la oposición a las violencias del capitalismo, el patriarcado, el racismo y la transfobia, ponen en marcha saberes para la organización colectiva. Durante estos meses de crisis política, neoliberal y sanitaria, esos saberes han circulado y se han hecho presentes en la esfera pública. Esto también es una "apertura”.

Apertura: acción y resultado de abrir o descubrir lo que está cerrado u oculto; sinónimos: iniciación, comienzo, principio (WordReference).

La apertura lleva casi un año en Chile y el espacio crucial donde sucede es la calle; su ocupación es la toma del espacio público. La apertura es potencialmente una revuelta de los sentidos. Nos indica un espacio por el cual podrían entrar, eventualmente, poéticas disidentes no solo a la pluma sino también a la práctica lectora y a los espacios/acciones que imagina. La apertura podría (o no) inaugurar un leer-distinto en línea con un escribir-distinto y un vivir-distinto, marcado por la abolición de las distintas formas de esclavitud racializada y sexualizada que son las bases del capitalismo desde sus orígenes. La apertura tiene la potencia de oponerse al sentido que le dan quienes gobiernan, para así crear un espacio donde, aprendiendo de los sobrevivientes, podamos crear una vida habitable.

La literatura también tiene sobrevivientes, y sus componentes son poéticas y políticas que, en vez de atrincherarse en los escritorios y los cuartos propios, ensayan otras maneras de ocupar lo público desde la vulnerabilidad. Pero el poder destituyente todavía no llega a la literatura y su circuito impreso y digital. Más que intacto, la pandemia ha profundizado las diferencias dentro del mundo del libro, y les autores 
enmudecen frente al capitalismo que sostiene las ediciones de sus libros. Mientras la destitución en el espacio social se organiza, estamos todavía a la espera de que el mundo literario pueda hablar sesudamente de cómo destituir los poderes que norman los vínculos literarios y enfrentar las consecuencias materiales colectivamente.

\section{Metáforas}

Desde el 18 de octubre de 2020, las calles y el mundo público han desbordado de correspondencias, metáforas y narrativas. Anoto algunas: metro/subterráneo/underground; despertar/ojo/mutilación; fuego/rabia/destitución; respiración/interrelación/ encierro/pandemia. Dejo aquí consignado parte de mi tren de pensamiento: el fuego, símbolo histórico de la resistencia mapuche, se extendió por la ciudad junto a banderas de otras múltiples nacionalidades que borraban el triunvirato europeizante de la bandera chilena, la genuflexión al imperio y el verde militar. Cuando Chile despertaba y abría los ojos a un vivir distinto, las fuerzas policiales mutilan los órganos del ver. Y apenas nos reunimos para respirarnos, experimentándonos como parte de un mismo cuerpo, llega una pandemia que nos niega esa posibilidad de interacción corporal tan necesaria para la asamblea.

En Estados Unidos, donde vivo, en la crisis permanente exacerbada por un gobierno racista cada vez más autoritario, las metáforas también se multiplican mortales. Las dos pandemias que azotan al imperio decadente, la del racismo sistemático y la del coronavirus, se desenvuelven en torno a la respiración. Como escribe Mary Louise Pratt:

¿Es insólito o una sobredeterminación que los dos eventos épicos que han revolucionado a Estados Unidos y el mundo - la pandemia [del coronavirus] y el asesinato de George Floyd - sean sobre la asfixia? De los 115000 muertos por coronavirus en Estados Unidos (un conteo que sabemos queda corto), casi todos murieron por asfixia y por fallas pulmonares, o por los devastadores efectos secundarios de los respiradores artificiales. Como Eric Garner y tantos otros, George Floyd también murió de una asfixia provocada por un policía que le cerró su vía respiratoria un tiempo excesivo hasta matarlo. Los clásicos linchamientos usaban el estrangulamiento con horcas; la versión contemporánea involucra las lumas. Son una y la misma, espectáculos públicos de estrangular las vías respiratorias como instrumentos del terror racial (la traducción es mía).

Base de la vida, en el acto de inhalar y exhalar, nuestros cuerpos se abren al otro. La respiración materializa la interdependencia de los cuerpos con el exterior. La cohabitación que experimentamos en el acto de respirar puede eventualmente ser el inicio de un proyecto político, de "la asamblea de los cuerpos", al decir de Alejandra Castillo, y que a pesar de la pandemia puede vivir en espacios abstractos, como la literatura. 
Otra metáfora más: si la muerte a distancia del disparo es el desprecio del (campo visual del) otro, la asfixia es la negación de la existencia colectiva.

Es posible que, frente a este desborde de metáforas en el espacio público, la narrativa realista sea incapaz de representar con profundidad personajes que no son individuos, sino masa, colectivo, voces múltiples, y aun así mantener las exigencias del formato libro y las presiones del mercado. Tal vez sea hora, pues, de desmarcar el libro, salirse de la fetichización de la palabra impresa para practicar una escritura que sea lenguaje-acción además de y a través del goce estético. Se trata de desbordar el marco y al autor/obra cifrados en ellos. Porque si bien la muerte del autor fue enunciada hace tiempo, la verdad es que el autor está más vivo que nunca. Pensemos, por ejemplo, en cómo los autores muertos, como Roberto Bolaño, siguen produciendo libros desde la ultratumba. Para separarnos de esa lógica del cadáver productivo, ¿qué significa que la literatura ponga en acción (enact) cuerpos que se respiran unos a otros en el acto estético?

Pienso aquí en dos metodologías que abren espacios emancipatorios en las prácticas estéticas: la transficción y la desapropiación. La transficción es el nombre con el que la cineasta Camila José Donoso denomina un ejercicio cinematográfico contra el deslinde de géneros y contra la especialización en el set de filmación para abrir espacios a que la transpiración, los afectos, los tactos supuren por la película. Por ejemplo, el guion de la película Casa Roshell fue creado a partir de grabaciones de audio tomados durante las noches por seis meses en el club Roshell, en Ciudad de México. En la filmación, que duró unos cuantos días, las mismas mujeres transgénero habitués del club actuaron las escenas que ellas mismas protagonizaron "en la vida real", situando una capa de ficción sobre la documental. El resultado es una película que escenifica la creación identitaria materializada a través de la mediación estética, borrando así no solo las fronteras entre personajes y personas, género sexual y fílmico, sino también una distinción sobre la que se construye la estética occidental, presentación y representación. En la cámara de Donoso, los métodos de trabajo multiplican el espacio de la autoría y la película materializa un deseo colectivo. ${ }^{13}$

Por su parte, la escritora mexicana Cristina Rivera Garza modela una propuesta a la urgente tarea de la literatura de cómo representar al otro sin silenciar los privilegios que distinguen a los escritores. Rivera Garza define la "desapropiación” como un lenguaje que se abre a incluir la voz de otros bajo estrategias de reescritura explícita esquivando "los riesgos obvios: subsumirlas a la esfera del autor mismo o reificarlas en intercambios desiguales signados por la ganancia o el prestigio". Lo explica más ampliamente así:

La desapropiación, así, desentraña la pluralidad que antecede a lo individual en el proceso creativo. Al hacerlo, la desapropiación expone el trabajo comunitario

13 Más sobre esto en Ríos, "A House Without Limits". 
de los practicantes de una lengua como base ineludible del trabajo creativo. [...] Lejos de ser una policía a la caza de apropiaciones varias, la estética desapropiativa produce estrategias de escritura que abrazan y dan la bienvenida a las escrituras de otros dentro de sí de maneras abiertas, lúdicas, contestatarias. Al generar, así, capas sobre capas de relación con lenguajes mediados por los cuerpos y experiencias de otro, las escrituras desapropiativas son escrituras geológicas (34).

Estos procedimientos llevan a repensar el material lingüístico con los que trabaja la escritora. Este tipo de textos reconoce el "origen plural de toda escritura [capaz de] construir, así, horizontes de futuro donde las escrituras se encuentren con la asamblea y puedan participar y contribuir al bien común" (24).

Ambas metodologías son un llamado a la acción con un componente utópico, estrategias que ponen en acción una crítica al sistema sobre el que opera el cine y la literatura para exponer las estructuras afectivas y materiales que componen los trabajos artísticos. En otras palabras, unta a la obra de su proceso de producción, dando cuenta de que sus materiales le pertenecen también a otros, creando no solo una deuda, sino también un acto estético que es un respirar en común. En la puesta en acción de las metodologías cinematográficas y literarias, estas dos mujeres abren espacios emancipatorios para investigar cómo las experiencias localizadas de los cuerpos en contacto y en su contexto informan las propuestas de futuro.

Podemos agregar a estas dos metodologías de trabajo la actual práctica editorial de escritoras y escritores sacándolas de las circulaciones exitistas para repensarlas como una puesta en acción de un cuerpo colectivo. No se trata únicamente de que, a través de la práctica editorial, una escritora "paga su deuda" con el colectivo, devolviendo así lo que extrae de su lenguaje. Por el contrario, como proponen Stefano Harney y Fred Moten en su Undercommons, se trata de hacer reventar la deuda, llevarla al límite para potencialmente crear contextos de lectura guiados por la apertura de los sentidos. Los nombres del futuro necesitan de tal entramado; no hay lectura posible de poéticas transformadoras sin contextos que le den cuerpo. Las editoriales tienen el potencial de materializar las vidas entre los engranajes de la maquinaria laboral, un saber plagado de belleza, peligro, precariedad, sutileza, obscenidad de donde surge un lenguaje compartido. Lo que pasa ahí no se puede reducir a la forma clásica de tomarse los medios de producción, se trata más bien del ideal de las artes ocultas de crear un cuerpo nuevo.

\section{El goce y el sacrificio}

Esta dèrive textual es interrumpida por dos acontecimientos que me obligan a reflexionar sobre el sentido de mis pasos anteriores. La primera es una llamada telefónica y la voz de una chilena-estadounidense a quien conocí protestando contra el toque 
de queda el octubre pasado afuera del Consulado en Nueva York. Tenemos un intercambio pendiente que involucra libros y drogas. Nos invita a escuchar una banda de salsa afuera del Bar de Toñita, vestigio de la comunidad latina en el Williamsburg gentrificado, barrio antes conocido como Los Sures. ${ }^{14}$ Antes de que el conductor del auto que tomamos pueda detenerse, ya sabemos que llegamos, pues los cuerpos en la calle interrumpen el flujo de los autos y buses. Al bajarnos nos golpea el calor húmedo de este clima subtropical en un día particularmente caliente. Hay personas regalando comida y en la calle sorbemos cervezas frías que sacamos como hordas de un inmenso refrigerador casi vacío. Sudando, con nuestro hijo de cachetes colorados en brazos, nos ponemos al lado de la banda: un teclado, tres trompetas, un contrabajo, un par de congas, timbales y cuatro micrófonos. Nuestro hijo de dos años baila con extraños que pronto tienen nombre, proveniencia, trabajo, acento, cuerpo y que nos llaman hermanos. Vienen de Colombia, Puerto Rico y los hay, como mi amiga que quién sabe dónde está ahora, nacidos de inmigrantes. Los músicos se limpian las frentes y nuestras mascarillas estilan sudor. Divisamos entre los cuerpos moviéndose al midtempo, a los autos de policía estacionándose a uno y otro lado de nuestro baile hirviente. La música se detiene y un uniformado recién salido del aire acondicionado, pistola al cinto, cámara de seguridad en el pecho, da unas instrucciones que apenas se escuchan. Por el micrófono, uno de los cuatro vocalistas dice en castellano: "Les pedimos que se suban a las veredas y despejamos la calle, así podemos volver a tocar y así ellos [los policías] también gozan”. Desarmarlos por el goce, apunta mi pareja. Un mensaje del futuro, pienso.

Cuando emerjo desde los pegajosos "comunes de abajo" a enfrentarme a mi computador, me encuentro en mi teléfono con el mensaje que el machi Celestino Córdova envió el centésimo día de su huelga de hambre. Su voz es fuerte a pesar de su debilitamiento, aunque se quiebra cuando materializa la palabra "sacrificio"; él, como autoridad espiritual, pone su cuerpo en sacrificio por la histórica lucha mapuche. Hacia el minuto, Córdova inserta en su mensaje algo similar a las posibilidades del otro utopismo, una ruptura temporal que hace coincidir el presente con el futuro. Dice: "Se acerca el tiempo de haber justicia favorable para todos los pueblos originarios en el mundo y para todos los pueblos oprimidos, por lo que así está predestinado sobrenaturalmente por los que ya estamos viviendo la nueva renovación en el mundo". Así es este mundo, en boca del machi, hay quienes viven oprimiendo, quienes luchan por justicia y quienes ya viven en la renovación.

Sacrificio y goce. Aquí me llevan estos pasos, a estos dos vectores organizativos y el espectro significante que hay entre ellos; ahí encuentro una primera materialización, donde las voces adquieren la forma de petición o mensajes y hacen coincidir

14 Parte de esa historia está registrada en el documental Los Sures, dirigida por Diego Echeverría en 1984, y en el más reciente Toñita's, que muestra la vida del último club social puertorriqueño en Williamsburg. 
términos que en la lógica neoliberal deberían ser contrarios y estar, por lo tanto, separados. Pero la partición entre goce y sacrificio es falsa e invalida la experiencia de la revuelta, de la asamblea. Los orificios que separan estos dos términos calan hondo hacia el underground, y allí se instalan cadenas significantes tan plurales como situadas en el arte visual que apenas esconden las capas de pintura en las calles aledañas a la Plaza Dignidad, en las pieles erizadas de quienes saltaron los torniquetes, en la caminata solitaria de quien se dirige sin nada en los bolsillos a la primera línea, en esas escrituras que le dan nombres al futuro. Porque podemos habitar ya, cuerpolenguaje, en ese mundo.

\section{Referencias}

Agamben, Giorgio. “On Potentiality”. Potentialities. Collected Essays in Philosophy. Stanford, Stanford University Press, 1999.

Ahmed, Sarah. Queer Phenomenology: Orientations, Objects, Others. Durham, Duke University Press, 2006.

Butler, Judith. El género en disputa. El feminismo y la subversión de la identidad. Buenos Aires, Paidós, 2007 [1990].

- - Notes Toward a Performative Theory of Assembly. Cambridge, MA, Harvard University Press, 2015.

Casa Roshell. Dirigida por Camila José Donoso. Cine Tonalá, 2017.

Castillo, Alejandra. Asamblea de los cuerpos. Santiago y Nueva York, Sangría Editora, 2019.

Claeys, Gregory y Lyman Tower Sargent. The Utopia Reader. Nueva York, New York University Press, 1999.

Debord, Guy. “Teoría de la deriva”. Internacional situacionista, vol. I: La realización del arte. Literatura Gris, 1999 [1958].

Gago, Verónica. La razón neoliberal. Economías barrocas y pragmática popular. Madrid, Traficantes de Sueños, 2014.

- - L L potencia feminista o el deseo de cambiarlo todo. Buenos Aires, Tinta limón, 2019. Glissant, Edouard. Caribbean Discourse. Charlottesville, University Press of Virginia, 1989.

Gordon, Avery. The Hawthorne Archive: Letters from the Utopian Margins. Nueva York, Fordham University Press, 2018.

Harney, Stefano y Fred Moten. The Undercommons: Fugitive Planning and Black Study. Wivenhoe / Nueva York / Port Watson, Minor Compositions, 2013.

Los Sures [Living Los Sures]. Dirigida por Diego Echeverría, 1984.

Pratt, Mary Louise. “Airways”. ConTactos, HemiPress, 2020. Disponible en https:// contactos.tome.press

Preciado, Paul B. Counter-Sexual Manifesto. Nueva York, Columbia University Press, 2018. 
Marchant, Julieta. "Para qué poetas en tiempos de miseria”. Jámpster online, 12 de noviembre de 2019.

Moreno, María. Oración. Buenos Aires, Random House, 2018.

Muñoz, José Esteban. Cruising Utopias. The Then and Now of Queer Futurity. Nueva York, New York University Press, 2009.

Rancière, Jacques, Proletarian Nights. Londres y Nueva York, Verso, 2012.

Ríos, Mónica Ramón. "El archivo espectral: el cine de tres mujeres chilenas frente a la nación (del cine mudo a la postdictadura)". Tesis para optar al grado de Doctora en Literatura. Rutgers University, 2016.

_- "Las metáforas son insuficientes". La Tempestad online, 30 de octubre de 2019.

- - "Una respuesta a Roberto Brodsky: Que la imaginación colectiva nos libre de sus trabalenguas". The Clinic online, 4 de diciembre de 2019.

- - "A House Without Limits: Framing Camila José Donoso's Casa Roshell through Disidentification and Disappropriation". Chilean Cinema in the World, editado por Carl Fischer y Vania Barraza. Detroit, Wayne State University Press, 2020.

Rivera Garza, Cristina. “Desapropiación para principiantes”. Literaturas y feminismo, editado por Mónica Ramón Ríos. Santiago de Chile, Sangría Editora, 2018.

Segato, Rita. Contra-pedagogías de la crueldad. Buenos Aires, Prometeo, 2018.

Toñita’s. Dirigida por Beyza Boyacioğlu y Sebastián Díaz. 2013.

Enviado: 13 de agosto de 2020 Aceptado: 29 de octubre de 2020 